\title{
Cutaneous Manifestations of Diabetes Mellitus
}

Michelle Duff, ${ }^{1}$ Olga Demidova, ${ }^{2}$ Stephanie Blackburn, ${ }^{1}$ and Jay Shubrook ${ }^{2}$

'OhioHealth O'Bleness Hospital, Athens, $\mathrm{OH}$

2Ohio University Heritage College of Osteopathic Medicine, Athens, $\mathrm{OH}$

Corresponding author: Jay Shubrook, shubrook@ohio.edu

DOI: $10.2337 /$ diaclin.33.1.40

(C)2015 by the American Diabetes Association. Readers may use this article as long as the work is properly cited, the use is educational and not for profit, and the work is not altered. See http:// creativecommons.org/licenses/by-nc-nd/3.0 for details.

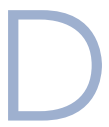

iabetes is the most common endocrine disorder, affecting $8.3 \%$ of the population (1). Skin disorders will be present in $79.2 \%$ of people with diabetes (2). A study of 750 patients with diabetes found that the most common skin manifestations were cutaneous infections $(47.5 \%)$, xerosis $(26.4 \%)$, and inflammatory skin diseases $(20.7 \%)$ (2). Individuals with type 2 diabetes are more likely than those with type 1 diabetes to develop cutaneous manifestations. Cutaneous disease can appear as the first sign of diabetes or may develop at any time in the course of the disease. This review provides a brief overview of skin conditions that primary care providers (PCPs) may encounter when treating patients with diabetes.

\section{Conditions Associated With Insulin Resistance}

\section{Acanthosis Nigricans}

Acanthosis nigricans (AN) is likely the most readily recognized skin manifestation of diabetes (3). It is present in up to $74 \%$ of obese adult patients and can be predictive of the existence of hyperinsulinemia (4). The presence of AN is a prognostic indicator for developing type 2 diabetes. There is also a possible genetic predisposition or increased sensitivity of the skin to hyperinsulinemia in different ethnic groups. At the same obesity rates, prevalence of AN is lowest in whites (0.5\%), higher in Hispanics (5\%), and even higher in African Americans (13\%) (5).

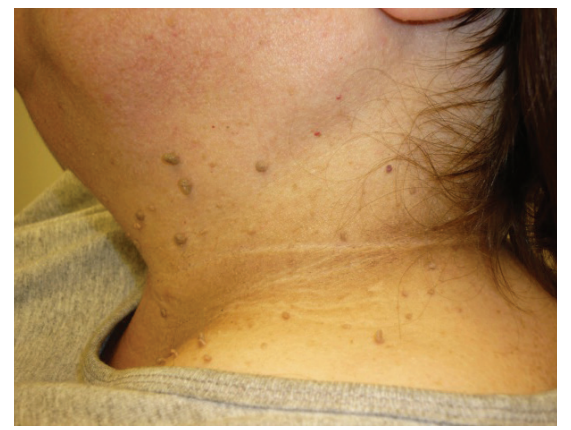

FIGURE 1. Acanthosis nigricans and acrochordans.

$\mathrm{AN}$ is a hyperpigmented velvety thickening of skin folds, presenting predominantly in the neck, axilla, and groin areas (Fig. 1). Possible additional presentations could include skin tags and hyperkeratosis. Heredity, obesity, endocrine disorders, certain drugs, and malignancy are associated with AN. Benign AN type 2 is related to type 2 diabetes, and pseudo-AN type 3 is associated with the metabolic syndrome. Type 2 diabetes-related AN has an insidious onset and initially presents as hyperpigmentation. Both underlying conditions present with insulin resistance (3). Children aged 8-14 years who had AN were found to have insulin resistance, and 25\% had disturbed glucose metabolism at the time of the study (6). Microscopically, AN presents as papillomatosis and hyperkeratosis (epidermis in irregular folds, exhibiting various degrees of acanthosis).

Treatment consists of treating the underlying cause. Significant weight loss resolves AN type 2 and type 3 . 
Topical or systemic retinoids and topical retinolytics may be used to manage symptoms (7).

\section{Acrochordrons}

Acrochordons, or fibroepithelial polyps, skin tags, and soft fibromas, are pedunculated outgrowths of normal skin on a narrow stalk, most commonly located on the eyelids, neck, axillae, and groin (Fig. 1). They are found in $-25 \%$ of adults, and their number and prevalence increases with age (6). Familial history, obesity and AN have been related to acrochordons; the relationship between hyperinsulinemia and skin tags has been well established (8).

Acrochordons are benign lesions, but may become symptomatic with abrasion or necrosis. Red or black skin tags are the result of twisting of the base, which cuts off the blood supply. The diagnosis of acrochordons is made by clinical appearance. Rarely, they may look suspicious for malignancy and should be sent for histological testing.

Treatment is usually cosmetic or for cases involving irritation. Excision may be performed with forceps, finegrade scissors, cryosurgery with liquid nitrogen, or electrodesiccation (9).

\section{Diabetic Dermopathy}

Population studies from Sweden demonstrate that diabetic dermopathy (DD) affects $33 \%$ of patients with type 1 diabetes, $39 \%$ of patients with type 2 diabetes, and $2 \%$ of control subjects (9). However, a more recent study found that DD is present in only $0.2 \%$ of people with well-controlled type 2 diabetes (10).

This condition presents as small $(<1 \mathrm{~cm})$, well-demarcated, atrophic depressions, macules, or papules on the pretibia and is considered to be a sign of insulin resistance (Fig. 2). Lesions heal and disappear within 1-2 years on their own, leaving atrophic hypopigmentation at the site of origin (3). Little is known about the relationship of DD to diabetes. On cadaveric skin biopsy, 4 of 14 samples demonstrated moderate to severe

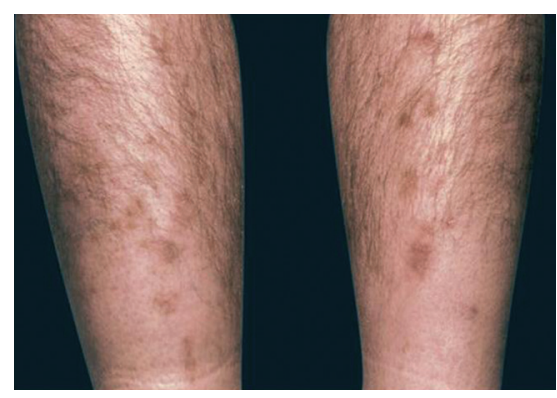

FIGURE 2. Diabetic dermopathy.

arterial wall thickening, and 11 of 14 samples demonstrated mild basement membrane thickening. Stain findings suggested the presence of hemosiderin and melanin depositions in the epidermis of affected patients (11).

No current treatment exists or is necessary for $\mathrm{DD}$, which is asymptomatic and does not lead to morbidity (3).

\section{Eruptive Xanthoma}

Eruptive xanthoma (EX) presents on the buttocks, elbows, and knees as sudden onset crops of yellow papules with an erythematous base (Fig. 3) (12). EX is rare and occurs more often in patients with poorly controlled type 2 diabetes. The sudden appearance of EX can be worrisome to patients and may prompt a visit to the physician.

These lesions can be the first sign of diabetes. The decrease in lipoprotein lipase activity seen in insulin-dependent diabetes results in an accumulation of serum triglycerides. Occasionally, when the serum triglyceride level reaches 2,000 $\mathrm{mg} / \mathrm{dL}$, lipids will deposit in the skin (13). Cutaneous presentation is associated with hypertriglyceridemia types I, III, IV, and V or secondary

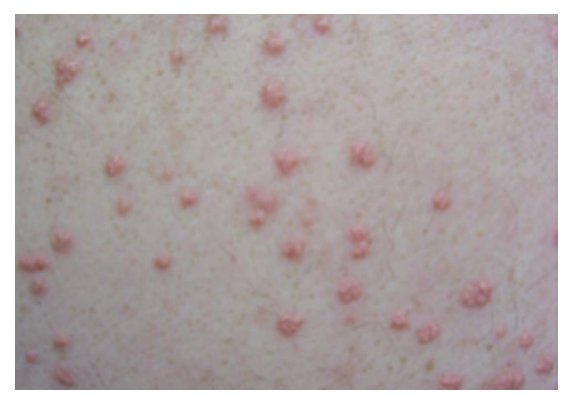

FIGURE 3. Eruptive xanthomas. hyperlipidemias. Types I, III, IV, and $V$ show high concentrations of very-low-density lipoprotein and chylomicrons. EX lesions tend to resolve spontaneously within weeks (14).

Diagnosis can be made clinically and confirmed with a biopsy of the lesions. It is important to obtain fasting lipid levels at presentation. People with EX are at higher risk from hypertriglyceridemia of early coronary artery disease and pancreatitis (13). Treatment should aim to lower the triglyceride concentration with diet modification and systemic medications to reverse this condition and decrease complications $(15,16)$.

\section{Rubeosis Facei}

Rubeosis facei (RF), a relatively common skin manifestation associated with diabetes, is a microangiopathic complication. It may go unnoticed by patients and physicians. However, if recognized, it should alert physicians to look for other microangiopathic complications such as retinopathy (17). RF presents as a flushing to the face. This condition is seen in 3-5\% of people with diabetes. In a study of 150 participants comparing facial redness association with diabetes, Gitelson et al. (18) showed that 59\% of patients with diabetes had markedly red faces compared to slightly red or not red (21 and 20\%, respectively).

The appearance of RF correlates with poor glucose control. No treatment is needed. Strict glycemic control can improve the appearance and prevent complications of microangiopathy in other organ systems $(12,19)$.

\section{Epidermal Necrolysis/Stevens- Johnson Syndrome}

Stevens-Johnson syndrome is a rare mucocutaneous necrotizing condition diagnosed in 1-6 cases per million people annually worldwide (20). A more severe form called toxic epidermal necrolysis is diagnosed at a rate of 0.4-1.2 cases per million people per year (21). Because of their similar etiology, pathogenesis, and clinical and histological presentation, it has been 
proposed to refer to both conditions as epidermal necrolysis (EN) (22).

In most cases, EN begins on first exposure to an inciting drug, within 8 weeks of the first dose. The dipeptidyl peptidase- 4 inhibitor sitagliptin has been associated with cases of Stevens-Johnson Syndrome (23). It could present with fever, headache, rhinitis, cough, malaise, burning eyes, and dysphagia (24). In 1-3 days, EN progresses to mucocutaneous ulcerations, necrosis and detachment of epidermis, severe stomatitis, and ocular involvement (25). Initial dusky red, pruritic macules are distributed symmetrically over the face, upper trunk, and proximal limbs, with distal limbs relatively spared (26). These lesions progressively coalesce and develop dark necrotic centers as they spread down the trunk. Nickolsky's sign-displacement of epidermis with lateral pressure - is positive over the blistering epidermis.

The pathophysiology of EN is under-investigated. Presence of a strong cell-mediated immunological response involving natural killer cells and $\mathrm{CD}^{+} \mathrm{T}$ lymphocytes specific for the causative agent has been noted. This reaction also involves monocytes and granulocytes (27). Other factors that amplify the reaction are still being investigated. The end result of hypersensitivity is a full-thickness keratinocyte apoptosis of the epidermis and mucous membranes (28). Although drugs and their components are the most common etiologies, viruses, Mycoplasma pneumoniae, and immunizations are also suspected. More than 100 medications have been identified as causes of EN (29). If a person develops EN while on sitagliptin, the drug's manufacturer recommends discontinuing therapy as soon as a hypersensitivity reaction is noted (30).

$\mathrm{EN}$ is a life-threatening emergency. Current treatments include withdrawal of all medications that would not be life-threatening. Discontinuation of medications started in the past 8 weeks is par- ticularly important. EN is treated supportively as a massive burn, with emphasis on preservation of intact skin and supportive symptomatic measures. Patients presenting with EN should be transferred to a qualified intensive care unit as soon as possible (31). Immunosuppressive drugs have not proven to be helpful (24).

\section{Conditions Associated With Type 1 Diabetes}

\section{Necrobiosis Lipoidica}

Necrobiosis lipoidica (NL) is rare, appearing in $0.3-1.6 \%$ of people with type 1 diabetes, more often in women than men $(12,32)$. Typical lesions of NL occur in young and middle-aged patients and present most commonly on the pretibial skin as irregular, painless ovoid plaques with a yellow atrophic center and a red to purple periphery. The lesions are usually multiple and bilateral. Lesions may ulcerate spontaneously or from trauma $(33,34)$. Of the patients with NL, $11-65 \%$ have type 1 diabetes at the time of cutaneous diagnosis (34). Ninety percent of people with NL who do not have diabetes eventually develop diabetes (mostly type 1 diabetes) (12). Glycemic control has no effect on the course of NL (16).

NL is a benign condition, and dermatology referral is not usually necessary. The cause of NL is currently unknown. Proposed causes are localized trauma, microangiopathy, immunoglobulins and fibrin deposition, and metabolic changes $(32,35)$. Although NL is benign, its appearance is cosmetically distressing to patients (Fig. 4).

The mainstay of treatment is currently steroids, either topical, intralesional, or, rarely, systemic. Steroids are cost-effective and have low side-effect profiles. Steroid use is beneficial to control the initial erythema in early lesions but fails to help with the atrophic component of the lesions and can worsen atrophy. Stockings are advised to help with stasis changes and protect from

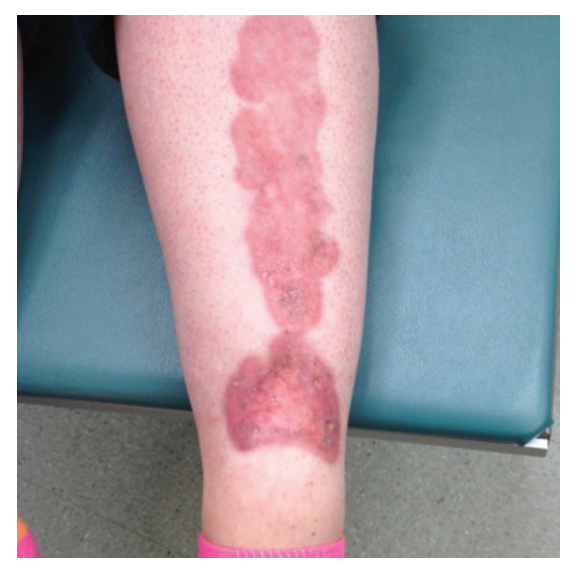

FIGURE 4. Necrobiosis lipoidica.

trauma (35). Other treatments that have been used include pentoxifyllin, cyclosporine, ticlopidine infliximab, and thalidomide. Some case reports have shown benefit from nicotinamide, clofazimine, cloroquine, and topical tretanoin. These later treatments do require dermatology referral to manage medications and potential side effects $(32,36)$.

\section{Vitiligo}

Vitiligo affects $0.3-0.5 \%$ of world population, making it the most common depigmenting disorder. Patients present with patches of depigmentation of skin and hair (Fig. 5).

Possible etiologies are both environmental and polygenetic. This condition affects males and females equally (37). Out of several subtypes, generalized vitiligo is most common. It is associated with autoimmune diseases in $20-30 \%$ of cases. The most common associations are with Hashimoto's thyroiditis, Grave's disease, rheumatoid arthritis, psoriasis, type 1 diabetes (usually adult-onset), pernicious anemia, systemic lupus erythematosus, and Addison's disease (38). A 2009 study of 50 patients with type 1 diabetes reported that $4 \%$ of subjects had vitiligo (39). Genetic vitiligo (GV) is most often a gradually progressive disorder and is unresponsive to treatment. However, some cases do stop progressing. GV complications are long duration, 


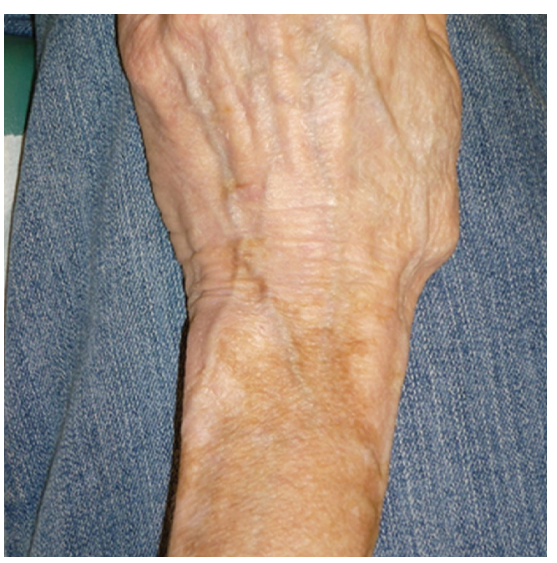

FIGURE 5. Vitiligo.

Koebner phenomenon, leukotrichia, and mucosal involvement (37).

Dermatological therapy attempts to reduce T-cell response and induce melanocyte migration and regeneration. Corticosteroids with ultraviolet $\mathrm{B}$ or calcineurin inhibitors or systemic psoralen and ultraviolet A (PUVA) light are first-line treatments. Calcipotriol, topical PUVA, excimer laser, corticosteroid pulse therapy, and surgical melanocyte grafting are some of the treatment options. These treatments are long and complicated by numerous side effects. Use of sunscreen is recommended but also controversial because of ultraviolet $B$ stimulation of melanocytes and the possibility of repopulation, as well as photo-adaptation of vitiligo-affected skin. Moderate exposure to sun is recommended.

The psychosocial impact of vitiligo can be substantial, and patient support groups are available. Numerous nontraditional treatments are attempted by patients but should be investigated for safety before administration (40).

\section{Bullosis Diabeticorum}

Bullosis diabeticorum, or diabetic bullae, are seen in $0.5 \%$ of individuals with type 1 diabetes. This condition is seen more often in men and in those with longstanding peripheral neuropathy. The lesions arise spontaneously and are primarily on the dorsa and the sides of the lower legs and feet. Occasionally, they are seen on the forearms and hands. The lesions present as clear bulla on non-inflamed bases. They are painless and contain sterile fluid. Lesion size can range from a few millimeters to a few centimeters (16).

Blister pathology is currently unknown. Diabetic bullae typically appear in individuals who have had type 1 diabetes for many years. However, this condition may be the first sign of diabetes (41). Lesions resolve on their own in 2-5 weeks. Differential diagnosis includes bullous pemphigoid, which can be ruled out by submitting a biopsy of the lesion for direct and indirect immunofluorescence. The lesions resemble those in acquired epidermolytic bullosa, porphyria cutanea tarda, autoimmune or impetiginous bullae, erythema multiforme, or drug eruption (42). Dermatologists often make the diagnosis of diabetic bulla; after diagnosis, this condition can be managed by PCPs.

The treatment is focused on infection prevention (19). If the bullae become large and symptomatic, they can be aspirated, leaving the roof intact to protect the skin barrier (16). Individuals may use saline compresses for symptomatic relief. Topical antibiotics or steroids are generally not necessary (41).

\section{Other Diabetes-Related Conditions}

\section{Psoriasis}

Psoriasis is a chronic, inflammatory, polygenic skin disorder with environmental triggers such as trauma, medications, and infection. Psoriasis is characterized by erythematous scaly papules and plaques with pustular and erythrodermic eruptions occurring most commonly in areas of friction such as scalp, elbows, knees, hands, feet, trunk, and nails. Koebner phenomenon is a well-documented factor, in which a plaque develops on the site of the injury. Histologically, Koebner phenomenon presents with alterations in epidermal growth (elongated rete ridges with dilated blood vessels, thinned suprapapillary plate, and differentiation), intermittent parakeratosis, and multiple biochemical, immunological, and vascular abnormalities (e.g., lymphocyte and neutrophil infiltration).

This condition can develop at any age, with the most common onset between 15 and 30 years of age; it is uncommon in people $<10$ years of age. It affects $2-3 \%$ of the U.S. population. Approximately $9 \%$ of people with diabetes (type 1 or type 2) has psoriasis (42). Recent research shows that psoriasis may raise predisposition for developing diabetes mellitus, just as it does for heart attack and stroke. A 13-year study with 52,000 participants concluded that people with psoriasis have a $49-56 \%$ greater risk of developing type 2 diabetes later in life (43).

Most people with psoriasis will be treated by a dermatologist. Treatment consists of topical and systemic immunomodulators, as well as ultraviolet light and laser application. Topical treatments are effective in most cases; however, they carry a $40 \%$ adherence rate because of time-consuming application and cosmetic inappropriateness (44). Both cream and ointment should be prescribed. Phototherapy with ultraviolet $A$, ultraviolet $B$, and psoralein has been used for several decades and has shown good response in mild cases (45).

\section{Lichen Planus}

Lichen planus is an uncommon disorder affecting $<1 \%$ of the general population. Onset is common in middle age (30-60 years of age). However, the prevalence of lichen planus in people with type 1 or type 2 diabetes has been noted to be $2-4 \%(39,46)$. Lichen planus may affect the skin (termed "cutaneous," with several variants), the oral cavity ("oral"), the genitalia ("vulvar" or "penile"), the scalp ("lichen planopilaris"), the nails, or the esophagus $(47,48)$.

Lichen planus presents as grouped, symmetric, erythematous to viola- 
ceous, flat-topped, polygonal papules distributed mainly in flexural aspects of arms and legs and rarely can appear on the trunk ("Blaschkoid" or "zosteriform") and inverse ("intertriginous") (48). Variants may include ulcerative and perforating types. Koebner phenomenon is common, and pruritus associated with lichen planus is intense and heals with postinflammatory hyperpigmentation.

Clinically, cutaneous lichen planus presents as flat-topped, violaceous papulosqamous eruptions on the skin. It is classically described as the "four Ps": pruritic, purple (violaceous), polygonal, and papules or plaques. Papules may be isolated and a few millimeters in diameter or may coalesce to form larger plaques (48). Fine white lines may be visible on the surface of papules or plaques and are known as "Wickham's striae." Diagnosis can be made based on clinical findings. If clinical recognition is questionable, a biopsy is indicated. Etiology of the condition is unknown. It is suspected that CD8+ T cells and a Th1 immune response (cell-mediated mechanism against keratinocytes) is involved (49).

Most cases of lichen planus will be managed by a dermatologist. Treatment of cutaneous lichen planus is focused on pruritus control (47). The potency of topical steroids used depends on the site involved. On the trunk and extremities, high-potency corticosteroids are indicated, whereas on the face and intertriginous areas, medium- to low-potency ointments are used. This is because of steroid-induced atrophy. Treatment efficacy should to be checked in 3 weeks. With generalized involvement, light therapy may be added to the treatment plan. Intralesional corticosteroids are applied to thicker lesions (49). Systemic glucocorticoids, phototherapy with PUVA and ultraviolet $B$, and oral acitretin can be beneficial in people who are not candidates for topical steroid therapy. Few studies have been conducted on treatments because of the typical spontaneous remission of lichen planus $(47,48)$.

\section{Xerosis}

Xerosis is another name for dry skin. It is the second most common skin manifestation in people with diabetes. In a study of 100 patients with diabetes and skin lesions, xerosis was present in $44 \%$ of the patients (50). Patients with renal disease also frequently suffer from xerosis.

No referral to a dermatologist is necessary for xerosis. PCPs should educate patients about the importance of skin hygiene, including applying fragrance-free creams or lotions within 3 minutes of bathing to trap moisture within the skin.

\section{Sclerederma Diabeticorum}

Sclerederma diabeticorum is a condition of thick, indurated, erythematous plaques occurring on the upper back and neck. Lesions may have erythema. This condition is seen in $-2.5-14 \%$ of individuals with diabetes (51). The condition is more common in obese middle-aged men with type 2 diabetes. Patients with scleroderma diabeticorum are often asymptomatic; however, neck and back pain may occur. The diagnosis is often made clinically, although a definitive diagnosis is confirmed by skin biopsy.

The pathogenesis of scleroderma diabeticorum is thought to be linked to increased stimulation of insulin and nonenzymatic glycosylation of collagen. This causes increased collagen cross-linking, rendering the collagen fibers resistant to degradation by collagenase and leading to increased amounts of collagen.

Treatments have showed limited benefits. Some treatment options include steroids, methotrexate, and ultraviolet light phototherapy $(15,52)$. Differential diagnosis includes Sclerederma Buschke, also associated with type 1 diabetes. Sclerederma Buschke presents as thickening mainly on the neck, shoulders, and upper limbs, often after an upper-respiratory infection. This condition clears spontaneously in a period of months or years. Women are affected more often than men. Sclerederma diabeticorum involves the fingers, hands, and trunk. It is in the family of diabetic thick skin called morphea and is the most severe, systemic sclerederma (53).

\section{Granuloma Annulare}

Granuloma annulare (GA) presents as erythematous to flesh-colored papules coalescing to form an oval or ring lesion. GA often presents asymptomatically but can cause pruritus or a burning sensation (54). The association between granuloma annulare and diabetes is controversial. One retrospective study showed a $12 \%$ association between GA and diabetes (55). Another study reported diabetes in $21 \%$ of 100 cases of generalized granuloma annulare (GGA) and in $9.7 \%$ of 1,350 cases of localized GA (56). Skin lesions may often precede diabetes. Struder et al. (55) suggest that patients with recurrent localized granuloma annulare or the disseminated form be given a glucose tolerance test.

The pathogenesis of GA is currently unknown. Treatment options are topical steroids, intralesional steroids, isotretinoin, dapsone, antimalarials, and phototherapy. Untreated lesions may spontaneously regress; this is more common in the localized form of GA than in the disseminated form (57). Localized forms can be treated easily and followed by PCPs. Recurrent GA or disseminated GA can be worked up by PCPs and referred to a dermatologist. GGA tends to be idiopathic. However, it has been associated with diabetes and with diseases such as autoimmune thyroiditis, HIV, hepatitis C, Epstein-Barr virus infection, sarcoidosis, and internal malignancies (58).

\section{Acquired Perforating Dermatosis}

Acquired perforating dermatosis presents as dome-shaped papules and nodules with hyperkeratotic plugs. This condition is characterized by 
the transepidermal elimination of some component of the dermis. The cutaneous perforating disorders have classically been divided into four types: elastosis perforans serpiginosa, reactive perforating collagenosis, perforating folliculitis, and Kyrle's disease. Perforating disorders have been associated with chronic renal failure, dialysis, and diabetes. Acquired perforating dermatitis is seen in both type 1 and type 2 diabetes $(15,16,59)$. In most cases, the renal disease is a complication of diabetic nephropathy (60). The lesions of acquired perforating dermatosis are most commonly seen on the trunk and extremities and tend to be pruritic.

It has been thought that the mechanism of action may be derived from epidermal trauma, a foreign-body reaction to the collagen in the dermis, or metabolic products from uremia $(59,61)$. Dialysis has not shown therapeutic value, but renal transplant has been shown to be effective in clearing the lesions (60). Treatment options include avoidance of scratching, topical or systemic steroids, phototherapy, retinoid, and antihistamines.

\section{Onychodystrophy}

Onychodystrophy presents as excessive nail thickening and deformity, which may cause accumulation of debris and subsequent infection of the toe that should be treated as a diabetic ulcer. Poorly fitting shoes may cause repeated trauma and worsening of the injured site (61). In patients with diabetes, onychodystrophy is the result of poor peripheral circulation and diabetic neuropathy. The condition itself may cause diabetic foot ulcers (62). Proper nail care, well-fitting shoes, and immediate attention to nail infections are important.

\section{Periungual Telangectasias}

Periungual telangectasias present as nail fold erythema, dilated blood vessels visible to the naked eye, fingertip tenderness, and thick cuticles. Telangectasias arise in the nail beds of people with diabetes after loss of capillary loops and dilation of remaining capillaries. The condition is present in up to $49 \%$ of people with diabetes (63). Some patients also experience fingertip tenderness. No treatment is necessary for this condition.

\section{Infections Associated With Diabetes}

\section{Cutaneous Infections}

Infections form the largest group of cutaneous conditions affecting people with diabetes. In a 2009 study of 50 patients, $55 \%$ of those with diabetes had infectious skin manifestations at some time (39). Another study reported a $61 \%$ prevalence rate in skin infections in people with diabetes (64). Cutaneous infections include candidiasis, dermatophytosis, and bacterial infections. These are described in more detail below.

\section{Candidiasis}

Mucocutaneous candidiasis is caused most commonly by Candida albicans and presents as red plaques with characteristic white adherent exudate and satellite pustules. The risk of infec- tion is increased with hyperglycemia, which favors Candida proliferation. Candidal vulvovaginitis is the most common of all cases, and perianal candidiasis is also common in both males and females. Other presentations include thrush (infection of oral mucosa and perleche), angular cheilitis, intertrigo (infection of skinfolds and erosio interdigitalis blastomysetica chronica), finger web space infection, paronychia (infection of soft tissue around the nailplate), and onichomycosis (infection of the nail) (3). Common cutaneous fungal infections are summarized in Table 1.

Rarely, critically ill patients with diabetic ketoacidosis (DKA) may be diagnosed with mucormycosis, an acute, severe, soft-tissue infection caused by Mucor, Rhizopus, and Absidia species. Saprophytic fungi prefer the low $\mathrm{pH}$ environments seen during DKA and thrive in hyperglycemia. Some fungi also utilize ketones as nutritional substance (3). An estimated $50-75 \%$ of cases of rhinocerebral mucormycosis occur in patients with diabetes (65).

Mucormycosis is progressive and poorly responds to systemic antifungals. Treatment options include itraconazole, fluconazole, amphotericine $\mathrm{B}$, and voriconazole. This condition is often fatal.

\section{Dermatophytosis}

Tinea or dermatophytoses are superficial infections of the skin, hair, and nails by fungus. Tinea corporis, tinea pedis (Fig. 6), and onychomycosis (Fig. 7) are common dermatophyte

TABLE 1. Common Cutaneous Fungal Infections

\begin{tabular}{ll}
\hline \multicolumn{1}{c}{ Infection } & \multicolumn{1}{c}{ Definition } \\
\hline Candidal vulvovaginitis & Infection of vaginal mucosa \\
\hline Perianal candidiasis & Infection of perineum and perianal area \\
\hline Thrush & Infection of the oral mucosa \\
\hline Perleche & Infection of labial commissures of mouth angles \\
\hline Intertrigo & Infection of skinfolds \\
\hline Erosion interdigitalis blastomysetica chronica & Infection of finger web space \\
\hline Paronychia & Infection of the soft tissue around the nail plate \\
\hline Onichomycosis & Infection of the nail
\end{tabular}




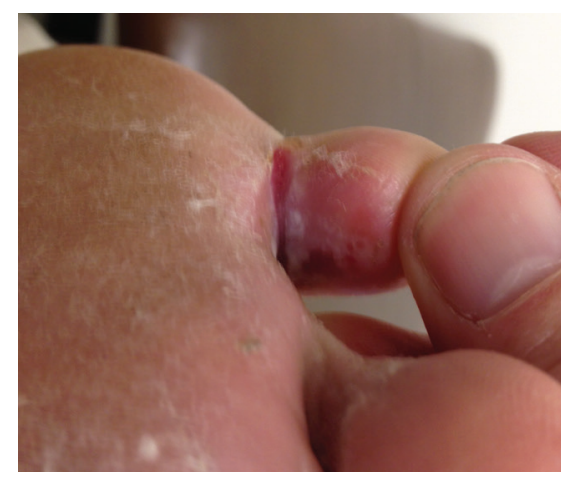

FIGURE 6. Tinea pedis.

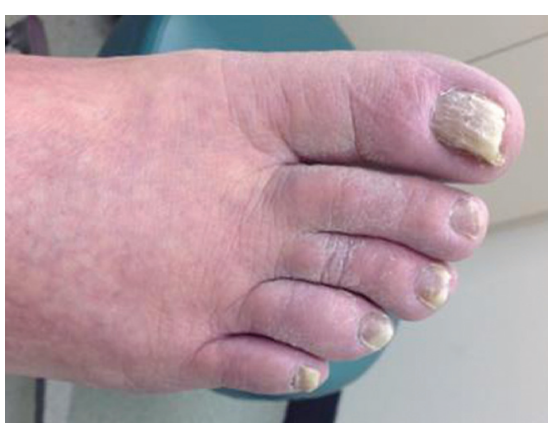

FIGURE 7. Onchiomycosis.

infections encountered in people with diabetes. In a 2013 study of 76 patients with tinea corporis, the main predisposing factor was xerosis (66). In a 2001 study of 171 people with diabetes compared with 276 control subjects, the most common infection in people with diabetes was tinea pedis, followed by distal subungual onychomycosis (65). This study did not show a correlation between dermatophytosis and duration or type of diabetes or its complications.

Trichophyton rubrum, Trichophyton mentagrophytes, and Trichophyton tonsurans are the most common dermatophytes. Because dermatophyte infections are so common in the general population, no dermatology referral is necessary. Treatment consists of topical antifungals or systemic antifungal medication. Table 2 summarizes common fungal infections and the topical and oral antifungal therapies used to treat them.

\section{Bacterial Infections}

Cutaneous bacterial infections are more common, as well as more severe,

TABLE 2. Treatment Options for Common Fungal Infections

\begin{tabular}{|c|c|}
\hline $\begin{array}{l}\text { Cutaneous Fungal } \\
\text { Infections }\end{array}$ & Treatment Options \\
\hline \multirow[t]{6}{*}{ Candidal vulvovaginitis } & Butoconazole vaginal $2 \%$ cream \\
\hline & $\begin{array}{l}\text { Clotrimazole vaginal 1\% cream, } 100 \text { mg } \\
\text { vaginal tablet }\end{array}$ \\
\hline & $\begin{array}{l}\text { Miconazole } 2 \% \text { cream, } 100 \text { mg vaginal } \\
\text { suppository, } 200 \text { mg vaginal suppository, } \\
1,200 \text { mg vaginal suppository }\end{array}$ \\
\hline & Ticonazole vaginal $6.5 \%$ ointment \\
\hline & Fluconazole $150 \mathrm{mg} \times 1$ dose \\
\hline & Nystatin vaginal 100,000 -unit vaginal tablet \\
\hline \multirow[t]{3}{*}{ Perianal candidiasis } & Miconazole topical 2\% cream, $4 \%$ cream \\
\hline & Miconazole insert 100 mg, 200 mg, 1,200 mg \\
\hline & Diflucan 150 mg by mouth $\times 1$ \\
\hline \multirow[t]{4}{*}{ Thrush } & Nystatin $100,000 \mathrm{U} / \mathrm{mL}$ \\
\hline & Clotrimazole $10 \mathrm{mg}$ \\
\hline & Miconazole 50 mg \\
\hline & Gentian violet topical $1 \%$ \\
\hline \multirow[t]{4}{*}{ Perleche } & $\begin{array}{l}\text { Nystatin/triamcinolone topical 100,000 } \\
\text { U/0.1\% }\end{array}$ \\
\hline & Clotrimazole topical 1\% \\
\hline & Miconazole topical 2\% \\
\hline & Ketoconazole topical 2\% \\
\hline \multirow[t]{5}{*}{ Intertrigo } & Fluconazole 200 mg daily $\times 2-4$ weeks \\
\hline & Itraconazole 200 mg daily $\times 2-4$ weeks \\
\hline & Ketoconazole 200 mg daily $\times 2-4$ weeks \\
\hline & $\begin{array}{l}\text { Terbinafine } 500 \mathrm{mg} \text { by mouth twice } \\
\text { daily } \times 6-8 \text { weeks }\end{array}$ \\
\hline & $\begin{array}{l}\text { Nystatin topical 100,000 units/g ointment, } \\
\text { powder, cream }\end{array}$ \\
\hline $\begin{array}{l}\text { Erosion interdigitalis } \\
\text { blastomysetica chronica }\end{array}$ & Clotrimazole $1 \%$ cream or solution \\
\hline \multirow[t]{4}{*}{ Paronychia } & Fluconazole 200 mg daily $\times 2-4$ weeks \\
\hline & Itraconazole 200 mg daily $\times 2-4$ weeks \\
\hline & Ketoconazole 200 mg daily $\times 2-4$ weeks \\
\hline & $\begin{array}{l}\text { Terbinafine } 500 \mathrm{mg} \text { by mouth twice } \\
\text { daily } \times 6-8 \text { weeks }\end{array}$ \\
\hline Onichomycosis & Terbinafine 250 mg \\
\hline
\end{tabular}

in people with diabetes. Diabetic foot ulcers are the leading type of morbidity in diabetes. They develop because of decreased sensation from diabetic neuropathy and unrecognized injury, with subsequent infection. White blood cell dysfunction resulting from increased glucose levels allows bacteria to proliferate. Staphylococcal folliculitis or skin abscesses are among the most common bacterial infections in uncontrolled diabetes. They respond well to antibiotics and surgical drainage. Pseudomonas aeruginosa is another common diabetic foot ulcer organism.

External ear canal infection caused by Pseudomonas aeruginosa is also frequent in people with diabetes. Pseudomonads thrive in moist 
environments full of oxygen. Lesions can be recognized by characteristic green-blue pigment, as well as fluorescence with Wood's lamp application. Microscopically, pseudomonads are identified as gram-negative rods. Patients may present with otalgia, otorrhea, hearing loss, and edema and erythema of the external ear canal.

Treatment consists of drying the area and applying topical antibiotics to uncomplicated infections. Malignant external otitis media requires immediate recognition and systemic antibiotics such as fluoroquinolones, plus an antipseudomonal antibiotic (e.g., antipseudomonal penicillin, antipseudomonal cephalosporin, monobactam, aminoglycoside, or carbapenem). Higher doses and surgical debridement are required to prevent spreading of the infection to bone and the nervous system (67). Urgent treatment of otitis externa is important because of its potential to rapidly spread to bone and cranial nerves, which could lead to mortality (68).

\section{Summary}

Diabetes is the most common endocrine disorder, and many cutaneous disorders are associated with diabetes. Knowledge of these skin conditions can aid PCPs in the diagnosis of diabetes and the treatment of its associated skin conditions. Most conditions can be managed by PCPs, but referral to a dermatologist may be warranted in some cases. As the incidence and prevalence of diabetes increases, skin manifestations associated with diabetes will become more common. Thus, PCPs should familiarize themselves with their presentation and treatment.

\section{Duality of Interest}

Jay. Shubrook has received research grant support from Sanofi Aventis and serves on the Global Primary Care Diabetes Board of Eli Lilly. No other potential conflicts of interest relevant to this article were reported.

\section{References}

1. Centers for Disease Control and Prevention. 2011 National Diabetes Fact Sheet. Available from http://www.cdc.
gov/DIABETES//pubs/factsheet11.htm. Accessed 25 August 2013

2. Demirseren DD, Emre S, Akoglu G, et al. Relationship between skin diseases and extracutaneous complications of diabetes mellitus: clinical analysis of 750 patients. Am J Clin Dermatol 2014;15:65-70

3. Kalus AA, Chien AJ, Olerud JE. Chapter 151: Diabetes mellitus and other endocrine diseases. In Fitzpatrick's Dermatology in General Medicine. 8th ed. Goldsmith LA, Katz SI, Gilchrest BA, Paller AS, Leffell DJ, Wolff K, Eds. New York, McGrawHill, 2012. Available online from http:// accessmedicine.mhmedical.com/content. aspx?bookid $=392 \&$ sectionid $=41138874$. Accessed 11 November 2014

4. Hud JA Jr, Cohen JB, Wagner JM, Cruz PD Jr. Prevalence and significance of acanthosis nigricans in an adult obese population. Arch Dermatol 1992;128:941-944

5. Stuart CA, Pate CJ, Peters EJ. Prevalence of acanthosis nigricans in an unselected population. Am J Med 1989;87:269-272

6. Banik R, Lubach D. Skin tags: localization and frequencies according to sex and age. Dermatologica 1987;174:180-183

7. Brickman WJ, Huang J, Silverman BL, Metzger BE. Acanthosis nigricans identifies youth at high risk for metabolic abnormalities. J Pediatr 2010;156:87-92

8. Kahana M, Grossman E, Feinstein A, Ronnen M, Cohen M, Millet M. Skin tags: a cutaneous marker for diabetes mellitus. Acta Dermato-Venereologica 1987;67:175-177

9. Ko CJ. Dermal hypertrophies and benign fibroblastic/myofibroblastic tumors. In

Fitzpatrick's Dermatology in General Medicine. 8th ed. Goldsmith LA, Katz SI, Gilchrest BA, Paller AS, Lefferr DJ, Wolf K, Eds. New York, McGraw-Hill, 2012. Available from http://accessmedicine. mhmedical.com/content.aspx?bookid $=392$ \&sectionid $=41138766$. Accessed 11 November 2014

10. Ragunatha S, Anitha B, Inamadar AC, Palit A, Devarmani SS. Cutaneous disorders in 500 diabetic patients attending diabetic clinic. Indian J Dermatol 2011;56:160-164

11. McCash S, Emanuel PO. Defining diabetic dermopathy. J Dermatol 2011;38:988-992

12. Paron NG, Lambert PW. Cutaneous manifestations of diabetes mellitus. Prim Care 2000;27:371-383

13. Martínez DP, Díaz JÓF, Bobes CM. Eruptive xanthomas and acute pancreatitis in a patient with hypertriglyceridemia. Int Arch Med 2008;1:6

14. Binić I, Janković A. Eruptive xanthomas associated with diabetes mellitus. Chin Med J 2009;122:2074-2075

15. Levy L, Zeichner JA. Dermatologic manifestation of diabetes. J Diabetes 2012;4:68-76
16. Ferringer T, Miller F 3rd. Cutaneous manifestations of diabetes mellitus. Dermatol Clin 2002;20:483-492

17. Namazi MR, Jorizzo JL, Fallahzadeh MK. Rubeosis faciei diabeticorum: a common, but often unnoticed, clinical manifestation of diabetes mellitus. ScientificWorldJournal 2010;10:70-71

18. Gitelson S, Wertheimer-Kaplinski N. Color of the face in diabetes mellitus: observations on a group of patients in Jerusalem. Diabetes 1965;14:201-208

19. Tabor CA, Parlette EC. Cutaneous manifestations of diabetes. Postgrad Med 2006;119:38-44

20. Chan HL, Stern RS, Arndt KA, et al. The incidence of erythema multiforme, Stevens-Johnson syndrome, and toxic epidermal necrolysis: a population based study with particular reference to reactions caused by drugs among outpatients. Arch Dermatol 1990;126:43-47

21. Rzany B, Mockenhaupt M, Baur S, et al. Epidemiology of erythema exsudativum multiforme majus, Stevens-Johnson syndrome, and toxic epidermal necrolysis in Germany (1990-1992): structure and results of a population-based registry. J Clin Epidemiol 1996;49:769-773

22. Ruiz-Maldonado R. Acute disseminated epidermal necrosis types 1, 2, and 3: study of sixty cases. J Am Acad Dermatol 1985;13:623-635

23. Pathak R, Bridgeman MB. Dipeptidyl peptidase-4 (DPP-4) inhibitors in the management of diabetes. P T 2010;35:509-513

24. Valeyrie-Allanore L, Roujeau J. Epidermal necrolysis (Stevens-Johnson syndrome and toxic epidermal necrolysis). In Fitzpatrick's Dermatology in General Medicine. 8th ed. Goldsmith LA, Katz SI, Gilchrest BA, Paller AS, Leffell DJ, Wolff K, Eds. New York, McGraw-Hill, 2012. Available from http://accessmedicine. mhmedical.com/content.aspx?bookid $=392 \&$ sectionid $=41138737$. Accessed 11 November 2014

25. Stevens AM, Johnson FC. A new eruptive fever associated with stomatitis and ophthalmia: report of two cases in children. Am J Dis Child 1922;24:526-533

26. Mockenhaupt M. Severe drug-induced skin reactions: clinical pattern, diagnostics and therapy. J Dtsch Dermatol Ges 2009; 7:142-160

27. Paquet $P$, Nikkels A, Arrese JE, Vanderkelen A, Piérard GE. Macrophages and tumor necrosis factor alpha in toxic epidermal necrolysis. Arch Dermatol 1994;130:605-608

28. Sassolas B, Haddad C, Mockenhaupt M, et al. ALDEN, an algorithm for assessment of drug causality in Stevens-Johnson syndrome and toxic epidermal necrolysis: comparison with case-control analysis. Clin Pharmacol Ther 2010;88:60-68 
29. Roujeau JC, Stern RS. Severe adverse cutaneous reactions to drugs. N Engl J Med 1994;331:1272-1285

30. Januvia [package insert]. Whitehouse Station, NJ, Merck \& Co., 2010

31. Ellis MW, Oster CN, Turiansky GW, Blanchard JR. A case report and a proposed algorithm for the transfer of patients with Stevens-Johnson syndrome and toxic epidermal necrolysis to a burn center. Mil Med 2002;167:701-704

32. Kota SK, Jammula S, Kota SK, Meher LK, Modi KD. Necrobiosis lipoidica diabeticorum: a case-based review of literature Indian J Endocrinol Metab 2012;16:614-620

33. Lowitt MH, Dover JS. Necrobiosis lipoidica. J Am Acad Dermatol 1991;25:735-748

34. O’Toole EA, Kennedy U, Nolan JJ, Young MM, Roger S, Barnes L. Necrobiosis lipoidica: only a minority of patients have diabetes mellitus. Br J Dermatol 1999;140:283-286

35. Roy S, Shayaan M. Unsightly rash on shin. necrobiosis lipoidica diabeticorum. J Fam Pract 2012;61:215-217

36. Cohen O, Yaniv R, Karasik A, Trau H. Necrobiosis lipoidica and diabetic control revisited. Med Hypotheses 1996;46:348-350

37. Hann SK, Park YK, Chun WH.

Clinical features of vitiligo. Clin Dermatol 1997;15:891-897

38. Spritz R. The genetics of generalized vitiligo. Curr Dir Autoimmun 2008;10:244-257

39. Mahajan S, Koranne R, Sharma S. Cutaneous manifestation of diabetes melitus. Indian J Dermatol Venereol Leprol 2003;69:105-108

40. Birlea SA, Spritz RA, Norris DA Chapter 74: Vitiligo. In Fitzpatrick's Dermatology in General Medicine. 8th ed. Goldsmith LA, Katz SI, Gilchrest BA, Paller AS, Leffell DJ, Wolff K, Eds. New York, McGraw-Hill, 2012. Available from http://accessmedicine.mhmedical.com/content . aspx?bookid $=392 \&$ sectionid $=41138776$. Accessed 11 Nomveber 201441. Lipsky BA, Baker PD, Ahroni JH. Diabetic bullae: 12 cases of a purportedly rare cutaneous disorder. Int J Dermatol 2000;39:196-200
42. Romano G, Moretti G, Di Benedetto A, et al. Skin lesions in diabetes mellitus: prevalence and clinical correlations. Diabetes Res Clin Pract 1998;39:101-107

43. Khalid U, Hansen PR, Gislason G, et al. Psoriasis is associated with increased risk of incident diabetes mellitus: a Danish nationwide cohort study. Eur Heart J 2012;33:360-361

44. Richards H, Fortune D, O'Sullivan T, Main C, Griffiths C. Patients with psoriasis and their compliance with medication. $\mathrm{J}$ Am Acad Dermatol 1999;41:581-583

45. Hönigsmann H. Phototherapy for psoriasis. Clin Exp Dermatol 2001;26:343-350

46. Puri N. A study on cutaneous manifestations of diabetes mellitus. Our Dermatology Online 2012;3:87

47. Le Cleach L, Chosidow O. Lichen planus. N Engl J Med 2012;366:723-732

48. Wagner G, Rose C, Sachse MM. Clinical variants of lichen planus. J Dtsch Dermatol Ges 2013;11:309-319

49. Lehman JS, Tollefson MM, Gibson

LE. Lichen planus. Int J Dermatol 2009;48:682-694

50. Goyal A, Raina S, Kaushal SS, Mahajan V, Sharma NL. Pattern of cutaneous manifestation in diabetes mellitus. Indian J Dermatol 2010;55:39-41

51. Cole GW, Headley J, Skowsky R. Scleredema diabeticorum: a common and distinct cutaneous manifestation of diabetes mellitus. Diabetes Care 1983;6:189-192

52. Thumpimukvatana N, Wongpraparut C, Lim HW. Scleredema diabeticorum successfully treated with ultraviolet A1 phototherapy. J Dermatol 2010;37:1036-1039

53. Van Hattem S, Bootsma AH, Thio HB. Skin manifestations of diabetes. Cleve Clin J Med 2008;75:772-782

54. Sahin MT, Türel-Ermertcan A, Oztürkcan S, Türkdogan P. Generalized granuloma annulare in a patient with type II diabetes mellitus: successful treatment with isotretinoin. J Eur Acad Dermatol Venereol 2006;20:111-114

55. Struder E, Calza A, Saurat J.

Precipitating factors and associ- ated disorders in 84 patients with granuloma annulare: a retrospective study. Dermatology 1996;193:364-368

56. Dabski K, Winkelmann R. Generalized granuloma annulare: clinical and laboratory findings in 100 patients. J Am Acad Dermatol 1989;20:30-47

57. Cyr PR. Diagnosis and management of granuloma annulare. Am Fam Phys 2006;74:1729-1734

58. Arroyo MP. Generalized granuloma annulare. Dermatol Online J 2003;9:13

59. Farrell A. Commentary: acquired perforating dermatosis in renal and diabetic patients. Lancet 1997;349:895-896

60. Maurice P, Neild GH. Acquired perforating dermatosis and diabetic nephropathy: a case report and review of the literature. Clin Exp Dermatol 1997;22:291-294

61. Mutluoglu M, Uzun G, Karabacak E. Toenail onychodystrophy of the diabetic foot. BMJ Case Rep 2012 Oct. 19;2012

62. Millikan LE, Powell DW, Drake LA. Quality of life for patients with onychomycosis. Int J Dermatol 1999;38(Suppl. 2):13-16

63. Landau J, Davis E. The small blood vessels of the conjunctiva and nail bed in diabetes mellitus. Lancet 1960;2:731-734

64. Romano C, Massai L, Asta F, et al. Prevalence of dermatophytic skin and nail infections in diabetic patients. Mycoses 2001;44:83-86

65. Higa M. Clinical epidemiology of fungal infection in diabetes. Nihon Rinsho 2008;66:2239-2244

66. Qadim HH, Golforoushan F, Azimi H, Goldust M. Factor leading to dermatophytosis. Ann Parisitol 2013;59:99-102

67. Yeung C, Lee K. Community acquired fulminant pseudomonas infection of the gastrointestinal tract in previously healthy infants. J Paediatr Child Health 1998;34:584-587

68. Soheilipour S, Meidani M, Derakhshandi H, et al. Necrotizing external otitis: a case series. B-ENT 2013;9:61-66 